\title{
World Heart Federation criteria for echocardiographic diagnosis of rheumatic heart disease-an evidence-based guideline
}

\author{
Bo Reményi, Nigel Wilson, Andrew Steer, Beatriz Ferreira, Joseph Kado, Krishna Kumar, \\ John Lawrenson, Graeme Maguire, Eloi Marijon, Mariana Mirabel, Ana Olga Mocumbi, Cleonice Mota, \\ John Paar, Anita Saxena, Janet Scheel, John Stirling, Satupaitea Viali, Vijayalakshmi I. Balekundri, \\ Gavin Wheaton, Liesl Zühlke and Jonathan Carapetis
}

\begin{abstract}
Over the past 5 years, the advent of echocardiographic screening for rheumatic heart disease (RHD) has revealed a higher RHD burden than previously thought. In light of this global experience, the development of new international echocardiographic guidelines that address the full spectrum of the rheumatic disease process is opportune. Systematic differences in the reporting of and diagnostic approach to RHD exist, reflecting differences in local experience and disease patterns. The World Heart Federation echocardiographic criteria for RHD have, therefore, been developed and are formulated on the basis of the best available evidence. Three categories are defined on the basis of assessment by 2D, continuous-wave, and color-Doppler echocardiography: 'definite RHD', 'borderline RHD', and 'normal'. Four subcategories of 'definite RHD' and three subcategories of 'borderline RHD' exist, to reflect the various disease patterns. The morphological features of RHD and the criteria for pathological mitral and aortic regurgitation are also defined. The criteria are modified for those aged over 20 years on the basis of the available evidence. The standardized criteria aim to permit rapid and consistent identification of individuals with RHD without a clear history of acute rheumatic fever and hence allow enrollment into secondary prophylaxis programs. However, important unanswered questions remain about the importance of subclinical disease (borderline or definite RHD on echocardiography without a clinical pathological murmur), and about the practicalities of implementing screening programs. These standardized criteria will help enable new studies to be designed to evaluate the role of echocardiographic screening in RHD control.
\end{abstract}

Reményi, B. et al. Nat. Rev. Cardiol. 9, 297-309 (2012); published online 28 February 2012; doi:10.1038/nrcardio.2012.7

\section{Introduction}

Rheumatic heart disease (RHD), the only long-term consequence of acute rheumatic fever (ARF), continues unabated among middle-income and low-income countries and in some indigenous communities of the industrialized world. At least 15 million people are estimated to be affected by RHD worldwide. ${ }^{1}$ The American Heart Association (AHA) has well-established clinical diagnostic criteria for ARF-the Jones criteria ${ }^{2}$-and, with some modifications and revisions, these guidelines have been accepted and utilized worldwide. ${ }^{3-5}$ No such widely accepted criteria exist for RHD.

The only cost-effective approach to controlling RHD is secondary prophylaxis in the form of penicillin injections every 3-4 weeks to prevent recurrent attacks of group A streptococcal infection that cause ARF and, thus, the worsening of RHD. ${ }^{6}$ However, the majority of patients who enroll into register-based programs are symptomatic with advanced disease, indicating that they have had a number

Competing interests

The authors declare no competing interests. of silent or undetected attacks of ARF. Patients with mild, asymptomatic RHD have the most to gain from secondary prophylaxis because, in the absence of ARF recurrence, the majority will have no detectable disease within $5-10$ years. ${ }^{7-9}$ Screening to detect asymptomatic cases is, therefore, an attractive strategy. a heart murmur in those with a history of ARF. Until the past decade, the stethoscope was the only noninvasive diagnostic tool available to physicians in low-income countries and in remote settings where ARF and RHD are most prevalent. However, detection rates were usually low. ${ }^{10-15}$ Echocardiography has proven to be more sensitive and specific than auscultation. ${ }^{16-22}$ RHD detected on echocardiography without an associated clinically pathological cardiac murmur is referred to as 'subclinical RHD. ${ }^{16}$ With the advent of portable technology, echocardiography can now be performed at a relatively low cost, even in remote settings. ${ }^{20}$ This development raises the possibility that people with previously undiagnosed RHD, including those without a known history of ARF, can be diagnosed
Traditionally, RHD was diagnosed by auscultating for
Green Lane Pediatric

and Congenital Cardiac Service, Starship Children's Hospital, Auckland, New Zealand (B. Reményi, N. Wilson, J. Stirling). Royal Children's Hospital, Australia (A. Steer). Maputo Heart Institute, Mozambique

(B. Ferreira). Fiji Ministry of Health, Fiji Islands (J. Kado). Amrita Institute of Medical Sciences, India (K. Kumar).

Stellenbosch University, South Africa

(J. Lawrenson). James Cook University, Australia (G. Maguire). Hôpital Européen Georges Pompidou, France (E. Marijon, M. Mirabel). University Eduardo Mondlane,

Mozambique

(A. O. Mocumbi). Federal University of

Minas Gerais, Brazil (C. Mota). WakeMed Hospital, USA (J. Paar). All India Institute of Medical Sciences, India (A. Saxena). Johns Hopkins Hospital, USA

(J. Scheel). Medical

Specialist Clinic,

Samoa (S. Viali).

Sri Jayadeva Institute of Cardiovascular Sciences and

Research, India (V. I. Balekundri) Women's and Children's Hospital, Australia (G. Wheaton) University of Cape Town, South Africa (L. Zühlke). Menzies School of Health Research, Australia (J. Carapetis).

Correspondence to:

B. Reményi

bo.remenyi@

menzies.edu.au 
and secondary prophylaxis started at an earlier stage of the illness than previously possible, thus potentially reducing morbidity and mortality.

Since 2004, the World Health Organization (WHO) has recommended echocardiographic screening for RHD in high-prevalence regions. ${ }^{23}$ In 2005, a joint WHO and National Institutes of Health $(\mathrm{NIH})$ working party established consensus case definitions for RHD, which were published 5 years later, in $2010 .^{24}$ The definitions were based on expert consensus, but have their limitations because they were not evidence-based, the full spectrum of morphological features of RHD were not considered, and in 2005 there was insufficient experience with normal echocardiographic findings in children. ${ }^{16}$ Since 2005, a number of countries-including Australia, Cambodia, Fiji, India, Laos, Mali, Mozambique, New Caledonia, New Zealand, Nicaragua, Pakistan, Samoa, South Africa, Tonga, and Yemen-have embarked on large-scale echocardiography-based RHD screening programs. ${ }^{16-19,21,22}$ Some of these screening programs used the 2005 WHO and NIH consensus definitions, but others used different criteria to define abnormality of both cardiac valve structure (morphology) and function (regurgitation or stenosis), often on the basis of local experience with RHD. This global experience, and the concern that echocardiography might be overly sensitive in some children with normal variation in valvular structure and function, has given impetus to develop an internationally endorsed evidence-based echocardiographic diagnostic guideline for RHD. In this article, we present the 2012 World Heart Federation (WHF) criteria for echocardiographic diagnosis of RHD. For ease of use in the clinical environment, a concise summary of these guidelines-containing the four key Boxes in this article-is available online as Supplementary Information.

\section{Intent of these guidelines}

Our primary aim in developing these guidelines was to define the minimum echocardiographic criteria for the diagnosis of RHD and to highlight the evidence on which these criteria are based. Use of these guidelines should enable rapid identification of RHD in patients who do not have a history of ARF. Importantly, the guidelines should allow for consistent and reproducible echocardiographic reporting of RHD worldwide and, therefore, facilitate epidemiologic studies and evaluation of interventions, such as group A streptococcal vaccine trials, aimed at reducing the worldwide burden of RHD. The guidelines are also intended to aid the long-term evaluation of minor echocardiographic lesions that do not meet the current echocardiographic criteria for definite RHD.

These guidelines are not intended for the diagnosis of carditis in the setting of ARF or for the diagnosis of RHD in patients with a history of ARF. In addition, this document does not contain recommendations on the management of ARF or RHD; for information on treatment, the reader is directed to local guidelines, or to the websites of the AHA,${ }^{2}$ WHO, ${ }^{3}$ Heart Foundation of Australia, ${ }^{4}$ and Heart Foundation of New Zealand. ${ }^{5}$

\section{Development of these guidelines}

An international advisory group of experts in RHD screening and echocardiographic manifestations of RHD was formed in 2009 (see the author list for this article). Under the auspices of the WHF, this group of 21 investigators from six continents developed evidence-based echocardiographic diagnostic guidelines for RHD. Expert panel members reported on echocardiograms online and systematic differences in reporting and diagnostic styles were identified. Via a series of web-based seminars, these differences were resolved and provisional echocardiographic criteria for RHD were agreed. A systematic literature review was performed using the Medline, Embase, and Cochrane databases to identify diagnostic features of established RHD by echocardiography, at cardiac surgery, and on postmortem examinations. The search terms "echocardiography", "surgery", "pathology", "mitral”, "aortic", "tricuspid", "valve", "normal", "regurgitation", "stenosis", "prolapse", "RHD” and "rheumatic" were optimally combined. The search was limited to papers published in the English language and was supplemented by careful review of the reference list of the relevant articles. A total of 3,218 abstracts and 170 full-text articles were reviewed; 108 were found to be directly relevant and are included in the reference list. All relevant articles were reviewed by at least two members of the panel. Evidence-based guidelines were finalized at a workshop in Thailand in 2011, where the expert panel members reviewed the 108 papers identified as directly relating to RHD and echocardiography. Results of completed, but not yet published, studies (by investigators who were part of the expert panel) were also critically reviewed. Whenever evidence for or against the provisional criteria was insufficient, a formal consensus method ${ }^{24}$ was used to reach agreement.

\section{Grading evidence}

The level of evidence was established and each recommendation was graded using the guidelines of the Scottish Intercollegiate Guidelines Network ${ }^{25}$ (Tables 1 and 2), as they seemed to be the most applicable to this diagnostic setting.

\section{Diagnostic criteria}

Echocardiographic findings should always be interpreted in conjunction with the patient's clinical findings and with consideration of the individual's pretest probability of RHD, which varies with geographical location (level $1+$ evidence), ${ }^{1}$ ethnicity (level $2+$ evidence), ${ }^{26,27}$ and living conditions (level 2+ evidence) (grade B recommendation). ${ }^{28,29}$ An individual's clinical history, including possible or probable ARF, should also be considered. In those with a history of definite ARF, any structural and functional abnormality of the valves must be considered to represent RHD until proven otherwise.

The concise echocardiographic criteria for 'definite RHD' and 'borderline RHD' are detailed in Boxes 1-3. The optimal settings for the echocardiography machine, which allow objective measurement, are summarized in Box 4. The echocardiographic features listed in Boxes 1-3 are not unique to RHD. Congenital, acquired, 
and degenerative heart disease should always be excluded as the etiology of mitral valve (MV) and aortic valve (AV) abnormalities before presuming rheumatic origin (grade D recommendation). Congenital cardiac defects are easily differentiated from RHD, as they have unique identifying features (for example, bicuspid AV or MV cleft). Degenerative conditions are rare in the young, and other acquired conditions (for example, infective endocarditis) can be differentiated from RHD on the basis of clinical findings (level 4 evidence).

RHD predominantly affects the left-sided cardiac valves, causing regurgitation, stenosis, or mixed hemodynamic effects. The tricuspid valve and (seldomly) the pulmonary valve can also be affected, but rarely (if ever) without MV involvement (99.3\% on echocardiography and $100 \%$ on postmortem examination have coexisting disease of the $\mathrm{MV} ;{ }^{30}$ level $1+$ evidence). Similarly, AV stenosis is rare in isolation (0-0.5\%; ${ }^{31-33}$ level $2+$ evidence). Hence, neither right-sided valve lesions nor aortic stenosis are included in the diagnostic criteria (grade B recommendation).

\section{Rationale and evidence for criteria Definite RHD}

Echocardiographic changes that meet the criteria for 'definite RHD' are considered to be rheumatic in origin, provided that other etiologies have been excluded by echocardiography and clinical context. In interpreting echocardiograms, the individual's pretest probability of RHD must be considered. The subcategories of 'definite RHD' (A-D) are listed below.

\section{Subcategory $A-R H D$ of the $M V$ with regurgitation}

Subcategory A of 'definite RHD' is defined as pathological mitral regurgitation and at least two morphological features of RHD of the MV. This subcategory has a grade $\mathrm{B}$ recommendation for its inclusion in the 'definite RHD' category.

MV disease in the form of regurgitation is the mostcommon manifestation of RHD in the young (level 2++ evidence). ${ }^{31-36}$ Echocardiographic, ${ }^{35-40}$ surgical, ${ }^{41-43}$ and postmortem anatomical ${ }^{44-46}$ studies have demonstrated that a combination of the morphological features (Box 3 ) is present in advanced disease (level 2+ evidence). Colloquial descriptions of the MVs—such as 'dog-leg', 'elbow', or 'hockey stick' deformities ${ }^{47}$-also portray a combination of morphological changes (thickening and restricted motion of the anterior MV leaflet; Figures 1 and 2).

\section{Subcategory $B-R H D$ of the MV with stenosis}

Subcategory B of 'definite RHD' is defined as mitral stenosis with a mean gradient $\geq 4 \mathrm{mmHg}$ and at least two morphological changes of RHD of the MV. This subcategory has a grade $\mathrm{B}$ recommendation for its inclusion in the 'definite RHD' category.

Worldwide, the most-common cause of MV stenosis is $\mathrm{RHD},{ }^{48-51}$ and the condition is associated with at least two morphological changes of RHD (level $2+$ evidence). ${ }^{51,52}$ Typically, leaflets are thickened and the posterior leaflet is relatively immobile and moves parallel during diastole
Table 1 | Levels of evidence, as defined in the guidelines of the SIGN25

\begin{tabular}{|c|c|}
\hline $\begin{array}{l}\text { Level of } \\
\text { evidence }\end{array}$ & Study description \\
\hline $1++$ & $\begin{array}{l}\text { High quality meta-analyses, systematic reviews of RCTs, or RCTs with } \\
\text { a very low risk of bias }\end{array}$ \\
\hline $1+$ & $\begin{array}{l}\text { Well-conducted meta-analyses, systematic reviews, or RCTs with a low risk } \\
\text { of bias }\end{array}$ \\
\hline $1-$ & Meta-analyses, systematic reviews, or RCTs with a high risk of bias \\
\hline $2++$ & $\begin{array}{l}\text { High-quality systematic reviews of case-control or cohort studies, } \\
\text { or high-quality case-control or cohort studies with a very low risk of } \\
\text { confounding or bias, and a high probability that the relationship is causal }\end{array}$ \\
\hline $2+$ & $\begin{array}{l}\text { Well-conducted case-control or cohort studies with a low risk of confounding } \\
\text { or bias, and a moderate probability that the relationship is causal }\end{array}$ \\
\hline $2-$ & $\begin{array}{l}\text { Case-control or cohort studies with a high risk of confounding or bias, } \\
\text { and a significant risk that the relationship is not causal }\end{array}$ \\
\hline 3 & Nonanalytic studies (for example, case reports or case series) \\
\hline 4 & Expert opinion \\
\hline
\end{tabular}

Table 2 | Grade of recommendation, as defined in the guidelines of the SIGN ${ }^{25}$

\begin{tabular}{ll}
\hline Grade* & Strength of evidence \\
\hline A & $\begin{array}{l}\text { At least one meta-analysis, systematic review, or RCT rated as 1++ } \\
\text { (see Table } 1 \text { for information about various levels of evidence) and directly } \\
\text { applicable to the target population; or a body of evidence consisting } \\
\text { primarily of studies rated as 1+, directly applicable to the target population, } \\
\text { and demonstrating overall consistency of results }\end{array}$ \\
\hline B & $\begin{array}{l}\text { A body of evidence including studies rated as } 2++ \text {, directly applicable } \\
\text { to the target population, and demonstrating overall consistency of results; } \\
\text { or extrapolated evidence from studies rated as } 1++ \text { or } 1+\end{array}$ \\
\hline C & $\begin{array}{l}\text { A body of evidence including studies rated as } 2+, \text { directly applicable } \\
\text { to the target population and demonstrating overall consistency of results; } \\
\text { or extrapolated evidence from studies rated as } 2++\end{array}$ \\
\hline D & Evidence level 3 or 4 ; or extrapolated evidence from studies rated as $2+$ \\
\hline $\begin{array}{l}\text { *The grade of recommendation relates to the strength of the evidence on which the recommendation is } \\
\text { based; it does not reflect the clinical importance of the recommendation. Abbreviations: RCT, randomized, } \\
\text { controlled trial; SIGN, Scottish Intercollegiate Guidelines Network. Permission obtained from SIGN } \odot\end{array}$ \\
2001-2011.
\end{tabular}

with the anterior MV leaflet. The second-most-common etiology of mitral stenosis is congenital MV stenosis, ${ }^{48,50}$ which is readily differentiated from RHD as it is frequently associated with abnormal papillary muscle arrangements and (in 84-97\% cases) with other congenital cardiac defects (level $2++$ evidence). ${ }^{53-56}$ Worldwide, RHD is still responsible for $95-99.3 \%$ of all MV stenoses in individuals aged $<50$ years (level $2++$ evidence) ${ }^{48,49}$ In those aged $>50$ years, nonrheumatic mitral annular calcification is a differential diagnosis of mitral stenosis that should be considered (level $2+$ evidence). ${ }^{49,57}$

\section{Subcategory C-RHD of the AV}

Subcategory C of 'definite RHD' is defined as pathological aortic regurgitation and at least two morphological features of RHD of the AV. This subcategory only applies to individuals aged $<35$ years and has a grade $\mathrm{B}$ recommendation for its inclusion in the 'definite RHD' category.

Although less common than isolated MV involvement, isolated disease of the $\mathrm{AV}$ is a recognized manifestation of RHD. A large study of 10,000 consecutive patients 


\section{Box 1 | 2012 WHF criteria for echocardiographic diagnosis of RHD}

\section{Echocardiographic criteria for individuals aged $\leq 20$ years}

Definite RHD (either A, B, C, or D):

- A) Pathological MR and at least two morphological features of RHD of the MV

- B) MS mean gradient $\geq 4 \mathrm{mmHg} *$

- C) Pathological AR and at least two morphological features of RHD of the AV ${ }^{\ddagger}$

- D) Borderline disease of both the AV and MVs

Borderline RHD (either A, B, or C):

- A) At least two morphological features of RHD of the MV without pathological MR or MS

- B) Pathological MR

- C) Pathological AR

Normal echocardiographic findings (all of A, B, C, and D):

- A) MR that does not meet all four Doppler echocardiographic criteria (physiological MR)

- B) AR that does not meet all four Doppler echocardiographic criteria (physiological AR)

- C) An isolated morphological feature of RHD of the MV (for example, valvular thickening) without any associated pathological stenosis or regurgitation

- D) Morphological feature of RHD of the AV (for example, valvular thickening) without any associated pathological stenosis or regurgitation

Echocardiographic criteria for individuals aged $>20$ years

Definite RHD (either A, B, C, or D):

- A) Pathological MR and at least two morphological features of RHD of the MV

- B) MS mean gradient $\geq 4 \mathrm{mmHg} *$

- C) Pathological AR and at least two morphological features of RHD of the AV, only in individuals aged $<35$ years ${ }^{\ddagger}$

- D) Pathological AR and at least two morphological features of RHD of the MV *Congenital MV anomalies must be excluded. Furthermore, inflow obstruction due to nonrheumatic mitral annular calcification must be excluded in adults. ‡Bicuspid AV, dilated aortic root, and hypertension must be excluded. ${ }^{\S}$ Combined AR and MR in high prevalence regions and in the absence of congenital heart disease is regarded as rheumatic.

Abbreviations: AR, aortic regurgitation; AV, aortic valve; MR, mitral regurgitation; MS, mitral stenosis; MV, mitral valve; RHD, rheumatic heart disease; WHF, World Heart Federation.

Box 2 | Criteria for pathological regurgitation

Pathological mitral regurgitation

(All four Doppler echocardiographic criteria must be met)

- Seen in two views

- In at least one view, jet length $\geq 2 \mathrm{~cm} *$

- Velocity $\geq 3 \mathrm{~m} / \mathrm{s}$ for one complete envelope

- Pan-systolic jet in at least one envelope

Pathological aortic regurgitation

(All four Doppler echocardiographic criteria must be met)

- Seen in two views

- In at least one view, jet length $\geq 1 \mathrm{~cm} *$

- Velocity $\geq 3 \mathrm{~m} / \mathrm{s}$ in early diastole

- Pan-diastolic jet in at least one envelope

*A regurgitant jet length should be measured from the vena contracta to the last pixel of regurgitant color (blue or red).

with RHD showed that isolated rheumatic AV disease occurs in $4.5 \%$ of individuals aged $\leq 18$ years and in $2.8 \%$ of individuals aged $>18$ years (level $2+$ evidence).$^{58}$ In smaller series, the prevalence has been reported to be 0-21.4\%. ${ }^{31-33,36,59-68}$ In AV disease, the presence of multiple morphological features (Box 3 ) enables confirmation of rheumatic etiology on gross inspection (level 2+ evidence) ${ }^{69}$ For consistency with the criteria for MV disease, and to increase specificity, the definite criteria for RHD of the AV require the presence of two rheumatic morphological features of the AV in addition to pathological aortic regurgitation. The two most-common differential diagnoses are bicuspid $\mathrm{AV}$ and aortic root dilatation, ${ }^{69}$ and both are easily differentiated on echocardiography. Other causes, such as endocarditis and other inflammatory carditis (systemic lupus erythematosus and ankylosing spondylitis), can be excluded by clinical context. Hypertension should also be excluded as an underlying etiology (level 4 evidence), although studies have shown conflicting associations between hypertension and trivial or greater aortic regurgitation. ${ }^{70-73}$ Both aortic regurgitation $^{72-74}$ and valvular thickening ${ }^{70,75}$ are more common with advancing age (level $2++$ evidence). However, on the basis of the CARDIA study ${ }^{71}$ - a population-based echocardiographic study of individuals aged 20-35 yearswe can extrapolate that the criterion for RHD of the AV remains highly specific for individuals aged up to 35 years. Of the 4,352 participants of the CARDIA study, ${ }^{71}$ only one had aortic regurgitation and a thickened AV, and none would have met the diagnostic criteria for definite RHD of the AV (level 2+ evidence).

\section{Subcategory D-multivalvular RHD}

Subcategory D of 'definite RHD' is 'borderline' disease of both the AV and MV, as defined below. In individuals aged $\leq 20$ years, this subcategory has a grade $\mathrm{C}$ recommendation for its inclusion in the 'definite RHD' category.

Worldwide, RHD remains the most-common etiology of combined AV and MV disease (level 2++ evidence). ${ }^{49,76,77}$ The morphological features that confirm rheumatic etiology take time to develop (level $2+$ evidence). ${ }^{35,40}$ Pathological aortic and mitral regurgitation, or pathological aortic regurgitation in combination with morphological changes of RHD, are extremely rare in children with normal cardiac anatomy; data indicate a prevalence of $0 \%$ in New Zealand ${ }^{78}$ and in Israel, ${ }^{79}$ and similar data have been found in the Australian gECHO study (J. Carapetis, unpublished data) (level $2++$ evidence). As a consequence, in individuals aged $\leq 20$ years who have a high pretest probability of RHD, pathological aortic and mitral regurgitation and pathological aortic regurgitation in combination with two rheumatic morphological changes of the MV, are considered to be rheumatic provided that no alternative explanation for these signs exist. The latter is also considered to be diagnostic for 'definite RHD' in individuals aged $\geq 20$ years on the basis of consensus opinion (level 4 evidence; see Box 1 for clarification).

\section{Borderline RHD}

The category of 'borderline RHD' only applies to individuals aged $\leq 20$ years; this age group is the least likely to have manifested sufficient echocardiographic features to meet the 'definite RHD' criteria because they can take time to develop (level 2+ evidence). ${ }^{35,40}$ The 'borderline RHD' category was established to improve the sensitivity of the echocardiographic criteria (at the expense of specificity) in individuals aged $\leq 20$ years, as this age group benefits the most from early detection and secondary prevention of RHD. Beyond the age of 20 years, mild valvular regurgitation is more common, ${ }^{71,72,74}$ and use of the 'borderline RHD' category is not, therefore, recommended for this age group (level 2+ evidence). Minor echocardiographic 
changes that meet the criteria for 'borderline RHD' represent early RHD in some individuals, ${ }^{35}$ and normal findings in others. ${ }^{78}$ Thus, when interpreting these echocardiographic findings, the individual's pretest probability (or risk) of RHD must be considered. The subcategories of 'borderline RHD' (A-C) are listed below.

\section{Subcategory A-morphological features of the MV}

Subcategory A of 'borderline RHD' is defined as at least two morphological features of RHD of the MV without pathological mitral regurgitation or mitral stenosis. This subcategory has a grade $\mathrm{C}$ recommendation for its inclusion in the 'borderline RHD' category.

Morphological features of RHD of the MV are likely to be rheumatic in origin, regardless of whether they are associated with hemodynamic effects, pathological regurgitation, or stenosis (level 4 evidence). Among 396 low-risk children in New Zealand, none had two morphological features of RHD of the MV (level 2+ evidence). ${ }^{78}$ Among 2,170 high-risk children in Mozambique, 50 (2.3\%) were identified as having two morphological features of RHD of the MV without meeting the criteria for pathological regurgitation or stenosis (level 2+ evidence) ${ }^{16}$ These studies support the hypothesis that the category 'borderline A' is part of the RHD spectrum.

\section{Subcategory $B-M V$ regurgitation}

Subcategory B of 'borderline RHD' is defined as pathological mitral regurgitation. This subcategory has a grade $\mathrm{B}$ recommendation for its inclusion in the borderline RHD' category.

Isolated pathological mitral regurgitation is four times as likely to occur in high-risk, compared with low-risk, children in New Zealand, supporting the hypothesis that it is part of the RHD spectrum (level $2++$ evidence). ${ }^{78}$ Morphological features of RHD can take time to develop and are more likely to be noted after a recurrence than during the primary ARF episode (level $2+$ evidence). ${ }^{35,40}$ Extrapolating evidence from surgical studies, approximately $5-7.5 \%$ of individuals with documented ARF and severe valvular disease might not meet the 'definite RHD' echocardiographic criteria. Despite severe valvular insufficiency of a single valve, two morphological features might not be present in individuals with acute carditis (level 2+ evidence). ${ }^{42,80}$ An echocardiographic study conducted in Brazil has also highlighted the low sensitivity of the 'definite RHD' criteria in young people receiving secondary prophylaxis. In this cohort of 27 patients with established chronic isolated disease of the MV, only $70.4 \%$ met the 'definite RHD' criteria; the remaining $29.6 \%$ only had one morphological feature of RHD (C. Mota, unpublished data; level 2++ evidence). These studies highlight the importance of the 'borderline RHD' category to improve the sensitivity of the echocardiographic criteria in the young.

\section{Subcategory $C-A V$ regurgitation}

Subcategory C of 'borderline RHD' is defined as pathological aortic regurgitation. This subcategory has a grade $\mathrm{B}$ recommendation for its inclusion in the 'borderline RHD' category.

\section{Box 3 | Morphological features of RHD}

\section{Features in the MV}

- AMVL thickening* $\geq 3 \mathrm{~mm}$ (age-specific) ${ }^{\ddagger}$

- Chordal thickening

- Restricted leaflet motion $\$$

- Excessive leaflet tip motion during systole

Features in the AV

- Irregular or focal thickening"

- Coaptation defect

- Restricted leaflet motion

- Prolapse

\section{Important considerations}

*AMVL thickness should be measured during diastole at full excursion.

Measurement should be taken at the thickest portion of the leaflet, including focal thickening, beading, and nodularity. Measurement should be performed on a frame with maximal separation of chordae from the leaflet tissue. Valve thickness can only be assessed if the images were acquired at optimal gain settings without harmonics and with a frequency $\geq 2.0 \mathrm{MHz}$.

FAbnormal thickening of the AMVL is age-specific and defined as follows: $\geq 3 \mathrm{~mm}$ for individuals aged $\leq 20$ years; $\geq 4 \mathrm{~mm}$ for individuals aged $21-40$ years; $\geq 5 \mathrm{~mm}$ for individuals aged $>40$ years. Valve thickness measurements obtained using harmonic imaging should be cautiously interpreted and a thickness up to $4 \mathrm{~mm}$ should be considered normal in those aged $\leq 20$ years.

\$Restricted leaflet motion of either the anterior or the posterior MV leaflet is usually the result of chordal shortening or fusion, commissural fusion, or leaflet thickening.

"Excessive leaflet tip motion is the result of elongation of the primary chords, and is defined as displacement of the tip or edge of an involved leaflet towards the left atrium resulting in abnormal coaptation and regurgitation. Excessive leaflet tip motion does not need to meet the standard echocardiographic definition of MV prolapse disease, as that refers to a different disease process. This feature applies to only those aged $<35$ years. In the presence of a flail MV leaflet in the young ( $\leq 20$ years), this single morphological feature is sufficient to meet the morphological criteria for RHD (that is, where the criteria state "at least two morphological features of RHD of the MV" a flail leaflet in a person aged $\leq 20$ years is sufficient).

"In the parasternal short axis view, the right and noncoronary aortic cusp closure line often appears echogenic (thickened) in healthy individuals and this should be considered as normal.

Abbreviations: AMVL, anterior mitral valve leaflet; $\mathrm{AV}$, aortic valve; $\mathrm{MV}$, mitral valve; $\mathrm{RHD}$, rheumatic heart disease.

Pathological aortic regurgitation (Box 2) in the absence of a well-defined valvular lesion (bicuspid valves or dilated aortic root) is extremely rare in children who are at low risk of ARF, RHD, or both. ${ }^{78,79}$ Among 1,360 children in Israel ${ }^{79}$ and 396 children in New Zealand ${ }^{78}$ with structurally normal hearts and low risk for RHD, none had pathological aortic regurgitation (Level 2++ evidence). Among 1,142 high-risk children in New Zealand, the prevalence of isolated pathological aortic regurgitation was $0.4 \%{ }^{19}$ This increased prevalence of pathological aortic regurgitation in high-risk school-aged children is, therefore, likely to represent early RHD. Without associated morphological features, the etiology cannot be confirmed; therefore, isolated pathological aortic regurgitation is categorized as 'borderline RHD' in people aged $\leq 20$ years.

\section{Criteria for pathological mitral regurgitation}

Wide experience differentiates physiological from pathological regurgitation. ${ }^{15,68,78,81-87}$ For a regurgitant jet to be considered pathological, all four criteria must be met (Box 2). The regurgitant MV jet must be pan-systolic, 
Box 4 | Echocardiography machine settings

- Nyquist limits for color-Doppler echocardiography should be set on maximum to avoid overestimation of jet length

- Images for assessment of valvular and chordal thickness should be acquired with harmonics turned off and probes with variable frequency set on $\geq 2.0 \mathrm{MHz}$; low frequency settings and harmonics exaggerate valve and chordal thickness

- Gain settings should be adjusted to achieve optimal resolution; images acquired with an excessive gain setting will not be suitable for objective valve thickness measurements

- All other settings (including depth, sector size, and focus) should also be optimized to achieve maximal frame rate (ideally 30-60 frames per second) and resolution and postmortem studies. The majority of these studies involved individuals described as having severe or advanced disease; however, standard definitions were absent and inconsistencies were noted in the terminology used. Morphological changes vary with the acuity of the disease ${ }^{40}$ and with age, ${ }^{34}$ as regurgitant lesions dominate in the young and mixed or stenotic lesions dominate with advancing age. ${ }^{34}$ The morphological criteria of the MV (in Box 2) is based on Carpentier's functional classification of valve disease, ${ }^{88}$ and are descriptive to avoid colloquialisms (such as 'dog-leg' and 'hockey-stick' deformity).

\section{Thickening of the MV leaflet}

high-velocity ( $\geq 3 \mathrm{~m} / \mathrm{s}$ ), visible from two views, and $\geq 2 \mathrm{~cm}$ in length from at least one view. The $2 \mathrm{~cm}$ (rather than the previously used $1 \mathrm{~cm}$ ) jet length increases specificity $^{15}$ and decreases sensitivity, and will reduce overdiagnosis of pathological mitral regurgitation. This $2 \mathrm{~cm}$ cut-off value is supported by data from healthy children in populations with a low prevalence of RHD. ${ }^{78}$ The requirements on Doppler echocardiography (high velocity and pan-systolic) ensure that closing volumes and trivial, but genuine, regurgitant jets ${ }^{81-83}$ are differentiated from clinically relevant valve regurgitation. All substantial regurgitant jets should produce a high velocity signal with a complete envelope on continuous-wave Doppler echocardiography. Data from New Zealand shows that, after the exclusion of individuals with congenital defects, $<0.5 \%$ of children who were at low risk for ARF, RHD, or both had pathological MV regurgitation according to the current criteria. ${ }^{78}$ The preliminary findings of the Australian gECHO study also support the low prevalence of pathological mitral regurgitation among healthy low-risk children (J. Carapetis, unpublished data).

By contrast, trivial MV regurgitation that does not meet all four criteria (in Box 2) is very common, ranging from $3 \%$ to $45 \%,{ }^{81-83}$ and should be considered to be physiological (level 2++ evidence) (grade B recommendation).

\section{Criteria for pathological aortic regurgitation}

Trivial aortic regurgitation that does not meet pathological criteria (Box 2) occurs in up to $2 \%$ of children (level $2++$ evidence), ${ }^{78,81-83}$ and becomes more frequent with advancing age (level $2++$ evidence).$^{71,72,74,82,84,85}$ For aortic regurgitation to be considered pathological, it must meet all four criteria (Box 2). The regurgitant jet must be pan-diastolic, high velocity ( $\geq 3 \mathrm{~m} / \mathrm{s})$, visible from two views, and $\geq 1 \mathrm{~cm}$ in length from at least one view. Such pathological aortic regurgitation is extremely rare in children with structurally normal hearts, with two studies reporting $0 \%$ prevalence ${ }^{78,79}$ and similar data being found in provisional analysis of the gECHO study (J. Carapetis, unpublished data) (level 2++ evidence).

Trivial aortic regurgitation that does not meet all four criteria for pathological aortic regurgitation should be considered physiological (grade B recommendation).

\section{Morphological features of RHD of the MV}

The morphological features of RHD of the MV have been examined in detail in echocardiographic, surgical,
Valvular thickening has been demonstrated to be a feature of RHD on echocardiography, ${ }^{35-40,52,86,87,89-95}$ at surgery, ${ }^{41,43,96}$ and on postmortem examinations (level 2++ evidence) ${ }^{45,97,98}$ Valvular thickening is often most marked at leaflet tips ${ }^{45,92}$ where the chords thicken and can become Thickening is present in $56-100 \%$ of patients with rheumatic carditis (level $2+$ evidence), ${ }^{38-40,43,87,89,92,95,99}$ and can also be associated with nodularity (or beading), ${ }^{35,38,39}$ which is often most pronounced during an episode of ARF and can later regress (level 2+ evidence). ${ }^{35,39}$

Normal valve thickness was shown to be age-related by Sahasakul et al. in a well-designed postmortem study (level $2++$ evidence), ${ }^{75}$ and correlation between surgical and echocardiographic measurements seems to be good if harmonic imaging is not used, as this modality increases apparent tissue thickness (level 2+ evidence). ${ }^{39,100-103}$

On the basis of data from a study of 280 healthy children in New Zealand, ${ }^{104}$ the normal echocardiographic thickness of the anterior MV leaflet (AMVL) in school-aged children is $1.12-2.92 \mathrm{~mm}$ (mean \pm SD of $2.02 \pm 2 \mathrm{~mm}$ ) (level $2++$ evidence). Two smaller pediatric studies also support the concept that normal valve thickness is $<3 \mathrm{~mm}$ (level $2+$ evidence). ${ }^{38-86}$

Webb et al. demonstrated that measuring the AMVL thickness during diastole in the parasternal long-axis agreement. ${ }^{104}$ To establish the normal range, they measured the thickest part of the leaflet on a frame with maximal separation from chordal tissue. The investigators noted that the measurements of the posterior MV leaflet were associated with a lower level of agreement. ${ }^{104}$

Studies of older age groups show increased mean AMVL thickness. Weissman et al. reported on 100 healthy individuals with a mean age of 41 years and found the mean AMVL thickness to be $2.38 \mathrm{~mm}( \pm 0.57 \mathrm{~mm}) .{ }^{105}$ The Framingham echocardiographic study ${ }^{106}$ assessed a total of 217 individuals (mean age 57 years), whose mean AMVL thickness was $3.2 \mathrm{~mm}$ (range and standard deviations were not stated). This observed increase of echocardiographic valve thickness relating to age is consistent with Sahasakul's postmortem anatomical study. ${ }^{75}$ The age-related recommendations in these guidelines were derived from the above-mentioned studies. ${ }^{38,75,86,104-106}$

Anterior MV thickness should only be objectively assessed if images were acquired without harmonic imaging and the gain settings were optimal for image incorporated into the leaflet tissue (level 3 evidence). ${ }^{45}$ view, was associated with a good level of interobserver 
a

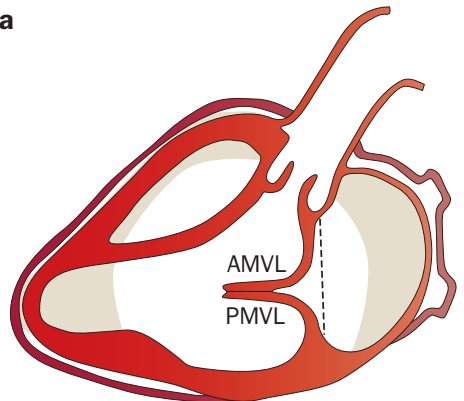

b

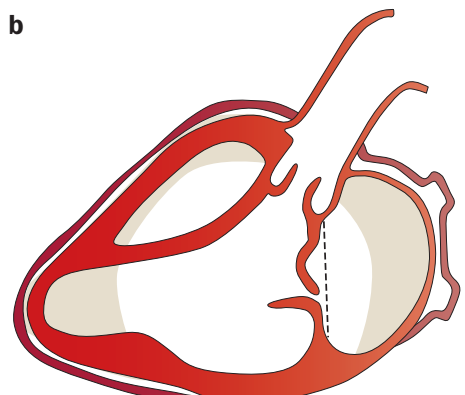

C

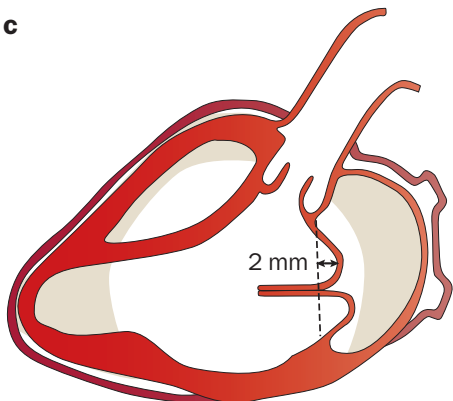

Figure 1 Schematic images of the MV in systole. a | A normal MV. b | RHD with excessive leaflet tip motion, which results in abnormal coaptation and regurgitation, but usually does not meet the echocardiographic definition of 'MV prolapse'. c | Echocardiographic MV prolapse, defined by $>2 \mathrm{~mm}$ billowing of the leaflet tissue into the left atrium. In echocardiographic MV prolapse (c), coaptation of leaflets often remains normal, as the free edges of the leaflet stay in apposition below the plane of the MV annulus. Abbreviation: AMVL, anterior MV leaflet; MV, mitral valve; PMVL, posterior MV leaflet; RHD, rheumatic heart disease.

resolution (grade B recommendation). Cut-off values for abnormally thickened valves are $\geq 3 \mathrm{~mm}$ for individuals aged $0-19$ years, $\geq 4 \mathrm{~mm}$ for individuals aged $20-39$ years, and $\geq 5 \mathrm{~mm}$ for individuals aged $\geq 40$ years (grade $B$ recommendation). Valve thickness measurements obtained using harmonic imaging should be cautiously interpreted and we recommended that a thickness up to $4 \mathrm{~mm}$ be considered normal in individuals aged $\leq 20$ years (grade D recommendation). Objective assessment of thickness of the posterior MV leaflet is less reproducible and, at this stage, is not included in the echocardiographic criteria (grade D recommendation).

\section{Chordal thickening}

Chordal thickening is a feature of RHD on echocardiographic, ${ }^{35-40,52,86,87,89-95}$ surgical, ${ }^{41,43}$ and postmortem ${ }^{45,62,97,99}$ examinations (level $2+$ evidence). Unlike valvular thickness, no standardized objective way of assessing chordal thickness on echocardiography exists, and its assessment remains subjective.$^{89}$ Chordal thickening can be identified in $100 \%$ of those with severe mitral stenosis requiring balloon valvotomy, ${ }^{89} 35-44 \%$ of those who require surgery for predominant mitral regurgitation, ${ }^{43}$ and in $37 \%$ of outpatients with RHD (C. Mota, unpublished data).

Chordal thickening must be subjectively assessed without utilizing harmonic imaging and at optimal gain settings (grade D recommendation).

\section{Excessive leaflet tip motion}

Excessive leaflet tip motion is defined as displacement of the tip or edge of the involved leaflet towards the left atrium, resulting in abnormal coaptation and regurgitation (Figure 1a,b). Excessive MV leaflet tip motion of the AMVL or posterior MV leaflet is the result of elongation or rupture of the primary chords (level $2++$ evidence $)^{41,42,44,80}$ and, together with annular dilatation, is the predominant mechanism of mitral regurgitation in the setting of acute rheumatic carditis (level 2+ evidence) ${ }^{80}$ Excessive MV leaflet tip motion has been well described in echocardiographic, ${ }^{34,35,37,38,41,80,87,95,107,108}$ surgical, $^{34,41-43,80,96,109-112}$ and anatomical ${ }^{44,98}$ studies (level 2+ evidence). Prevalence among patients with RHD ranges from $11 \%$ to $97 \%,{ }^{34,35,37,41-43,80,95,108,109,111}$ depending on the population that is sampled. Excessive MV leaflet tip motion is most common among young rheumatic patients with pure mitral regurgitation, ${ }^{34,40}$ and is less common beyond the third decade of life, when mitral stenosis predominates (level $2+$ evidence) ${ }^{34}$

Although the above definition of excessive leaflet tip motion is the surgical definition of valvular prolapse, as described by Barlow and Carpentier, ${ }^{80,88,113,114}$ the standard echocardiographic definition of MV prolapse does not need to be met in the setting of RHD, as that refers to a different disease process. MV prolapse is a degenerative condition that is common with advancing age, and is defined as $\geq 2 \mathrm{~mm}$ billowing (or hooding) of the body leaflet tissue into the left atrium during systole, which must be visible from at least two echocardiographic views, including the parasternal long-axis view (Figure 1c). ${ }^{115}$ The free edges of the leaflet generally remain in apposition below the plane of the MV annulus, ${ }^{88,113,114}$ and MV prolapse might or might not lead to MV regurgitation. ${ }^{115}$ Billowing of the leaflet bodies is seldom the predominant feature of rheumatic carditis. ${ }^{114}$

In the pediatric population, chordal rupture (an etiology of excessive leaflet tip motion) predominantly occurs in the setting of rheumatic carditis and is present in $7-17 \%$ of patients undergoing rheumatic MV repair (level 2++ evidence). ${ }^{40,41,43,80}$ Only a few case reports exist where chordal rupture was attributed to other etiologies, such as severe connective tissue disorders or myxomatous degeneration, in children. ${ }^{116,117,11}$ In adults, the most-common etiology of chordal rupture is myxomatous degeneration, followed by endocarditis, and then RHD (level 1+ evidence). ${ }^{119}$

Excessive leaflet motion of the anterior or posterior MV leaflet tips is a morphological feature of RHD (grade B recommendation). This criterion applies to individuals aged $<35$ years (grade $\mathrm{C}$ recommendation) as, beyond the third decade of life, RHD is rarely characterized by excessive leaflet motion and almost never without associated restriction of other leaflet scallops and chordal or valvular thickening. In the presence of a flail leaflet in the young ( $\leq 20$ years), only one morphological feature is required to meet the morphological criteria for RHD, if other causes have been excluded by clinical assessment (grade $\mathrm{C}$ recommendation). 


\section{REVIEWS}

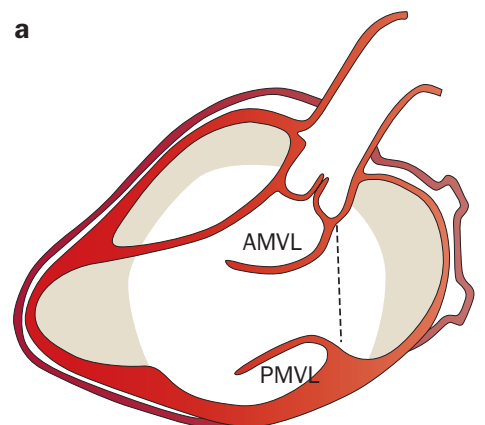

b

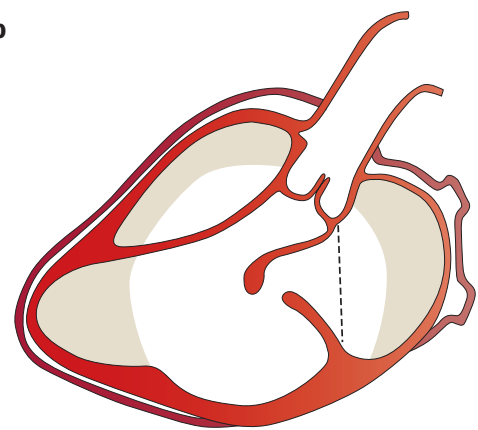

Figure 2 | Schematic images of the MV in diastole. a | A normal MV. b | A rheumatic $M V$ with thickened and restricted anterior and posterior leaflets. Abbreviations: $\mathrm{AMVL}$, anterior MV leaflet; MV, mitral valve; PMVL, posterior MV leaflet.

\section{Restricted MV leaflet motion}

Restricted leaflet motion is the result of chordal shortening, chordal fusion, leaflet thickening, calcification, or commissural fusion (level $2+$ evidence). ${ }^{51,88}$ This condition is one of the hallmarks of RHD and is observed in 100\% of patients with pure mitral stenosis or mixed lesion of the MV (level 2++ evidence). ${ }^{34,35,92}$ In the setting of predominant mitral regurgitation, restricted MV leaflet motion is present in $20-60 \%$ of patients. ${ }^{35,38-42,112}$ This phenomenon is more common in individuals with chronic or established RHD, ${ }^{34,35}$ and is more prevalent with advancing age (level 2+ evidence). ${ }^{34,40}$ Generally absent during the first episode of $\mathrm{ARF},{ }^{35}$ restricted MV leaflet motion develops with time or recurrences. ${ }^{35}$

Restricted MV leaflet motion is diagnosed with realtime diastolic imaging, and can affect either the anterior, posterior, or both leaflets. When the anterior leaflet is affected in association with valvular thickening, the terms 'hockey stick, ${ }^{47}$ 'dog-leg', or 'elbow' deformity have been used and reflect the combination of these two morphological changes (Figure 2). Restricted motion of the posterior MV leaflet is a hallmark of RHD and, when severe, gives rise to the classic immobile appearance.

Restricted leaflet motion (the result of chordal shortening, chordal fusion, leaflet thickening, calcification, and commissural fusion), is one of the morphological features of RHD of the MV leaflet (grade B recommendation).

\section{Morphological RHD features of the AV}

Isolated disease of the AV is relatively rare and a paucity of echocardiographic studies that systematically describe morphological changes associated with rheumatic AV disease exists in the English literature. ${ }^{36,95,120}$ The morphological changes associated with RHD of the AV have been well described in surgical studies that have focused on AV repair. ${ }^{121-126}$ As a result, the echocardiographic criteria for morphological features of AV disease are extrapolated from surgical and postmortem findings and are based on Carpentier's functional classification of AV disease. ${ }^{88}$

Irregular or focal thickening, coaptation defect, restricted leaflet motion, and excessive leaflet motion are echocardiographic features of RHD of the AV. However, these characteristics are not unique to RHD and other etiologies should be excluded by echocardiography and clinical assessment (grade B recommendation).

\section{AV thickening}

The normal AV is a very thin structure $0.67 \pm 0.21 \mathrm{~mm}$ (mean $\pm \mathrm{SD}$ ), as established on postmortem examinations. ${ }^{75}$ Because the valve is so thin, standardized, objective echocardiographic measurements of its thickness have not been established. One large, population-based echocardiographic study of adults showed that subjective assessment of $\mathrm{AV}$ thickness is acceptable and is associated with good interobserver and intraobserver agreement (level 2+ evidence). ${ }^{127}$ Surgical studies have demonstrated that aortic leaflet thickening is present in $41-100 \%$ of individuals with rheumatic aortic regurgitation (level $2++$ evidence). ${ }^{121-126}$ Of these surgical studies, the one in which the oldest population (mean age 51 years) was assessed had the highest prevalence of AV thickening, ${ }^{126}$ and the study in which the youngest cohort of rheumatic patients (mean age 12 years) was observed demonstrated the lowest prevalence of surgically relevant valvular thickening. ${ }^{121}$ This thickening can be nodular or irregular, ${ }^{64}$ commonly occurs at the free edge of the AV, and can lead to abnormal coaptation and aortic regurgitation. Surgically restoring normal valve thickness alone can improve valvular coaptation. ${ }^{88,122,126}$

\section{Coaptation defect}

Surgical studies have described the most-common causes of rheumatic aortic regurgitation as leaflet retraction and rolling of the leaflet edges that result in a central (often triangular shaped) coaptation defect that can be visualized on 2D echocardiography (level $2+$ evidence). ${ }^{121-125}$

\section{Restricted leaflet motion}

In an echocardiographic study, restricted aortic-leaflet motion was found in $76 \%$ of 25 patients and was judged to be the predominant mechanism of rheumatic aortic regurgitation (level 2 +evidence). ${ }^{120}$ In this echocardiographic study, only one patient had excessive leaflet motion and the remainder (20\%) had normal leaflet motion. In individuals with normal leaflet motion, aortic regurgitation was probably the result of leaflet retraction and thickening. The echocardiographic finding of restricted leaflet motion corresponds to the surgical description of 'commissural fusion' with or without associated valvular thickening and calcification. In surgical studies, a minor degree of commissural fusion is surprisingly prevalent, even in predominantly regurgitant valves, and ranges from $11 \%$ to $73.8 \%$ (level $2+$ evidence). ${ }^{121-123}$ Similarly to AV thickening, commissural fusion was less frequent in children. ${ }^{121}$

\section{Prolapse or excessive leaflet motion}

Excessive mobility or prolapse of the AV is present when aortic cusp tissue extends below the level of the aortic annulus, and has been demonstrated to be a feature of RHD in echocardiographic, ${ }^{36,95,120}$ surgical, ${ }^{121-123}$ and pathological ${ }^{44}$ studies (level $2++$ evidence). AV prolapse should only be diagnosed when associated with pathological (commonly eccentric) regurgitation. Prolapse of the aortic leaflet is not specific to RHD and care must be exercised to exclude other etiologies by taking clinical context into consideration. ${ }^{44,128}$ In a cohort of individuals 
with acute rheumatic carditis, $11 \%$ of 66 patients (mean age 12.5 years) had AV prolapse demonstrated on echocardiography. ${ }^{95}$ Surgical studies that report on AV repair techniques quote the prevalence of prolapse in rheumatic aortic regurgitation to be $3.8-59 \% .{ }^{121-123}$ Of the three surgical studies, the highest prevalence was in the study with the youngest population (mean age 12 years), ${ }^{121}$ and the lowest prevalence was in the oldest population (mean age 40 years). ${ }^{122}$

\section{Limitations of echocardiographic criteria}

The 2012 WHF criteria for echocardiographic diagnosis of RHD aim to differentiate mild RHD from normal findings on echocardiography. They recognize that more-sophisticated imaging modalities and quantitative techniques might not be possible using the portable echocardiographic machines available in many resourcepoor settings. The criteria are, therefore, formulated on the basis of 2D, color-Doppler, and continuous-waveDoppler echocardiography. The criteria to differentiate physiological from pathological regurgitation are derived from historical studies, some of which date back a number of decades; however, they have been tested on large cohorts of healthy children over the past 5 years. Over the past 10 years, advances in the quantification of valvular regurgitation and stenosis have occurred. The vena contracta, the proximal isovelocity surface area, and the effective regurgitant orifice area can now all be measured to allow for grading of severity of valvular regurgitation. These newer techniques allow for the differentiation of mild from moderate and moderate from severe disease. However, to date, little attention has been focused on assessing their utility to differentiate physiological from pathological regurgitation. Importantly, their use in the setting of RHD is limited, owing to the eccentric nature of rheumatic regurgitant jets. Abnormal loading conditions - such as fluid overload, hypertension, and dehydration - can alter the severity of regurgitation regardless of the method used (for example, might alter regurgitant jet length). Fortunately, loading conditions are generally normal in otherwise-healthy children who undergo routine echocardiographic screening for RHD. Structural or morphological changes are also recognized to often only affect leaflet segments. As a result, in children, pathology can be missed with 2D imaging if only standard, adult-style echocardiographic views are assessed. Technical pitfalls of image acquisition and echocardiographic machine settings must always be addressed at screening sites, as image qualityul is operatordependent and can substantially affect the interpretation of images. These 2012 WHF echocardiographic criteria will likely require substantial modification as technological advancements and increased affordability of more-sophisticated portable machines allow for better differentiation of physiological from pathological echocardiographic findings in resource-poor countries.

\section{Implications for RHD screening}

Value of echocardiography screening programs

To date, perhaps the greatest impact of echocardiography screening programs for RHD has been to stimulate interest in, and advocacy for, RHD control. Echocardiography has a role in defining RHD disease burden for various regions, which assists health ministries to set priorities. In addition, by identifying previously undiagnosed cases of RHD, enabling these patients to commence secondary prophylaxis, echocardiography also has a substantial impact on individual patients.

However, the expectation that echocardiographic screening will directly lead to reductions in RHD disease burden has yet to be proven. To date, investigators have focused on defining disease prevalence through sentinel studies, rather than evaluating the larger-scale impact on disease control. Important gaps remain in our knowledge that limit our ability to make definite recommendations about how, and in what settings, echocardiographic screening for RHD should be undertaken, and how abnormal findings should be managed.

\section{Requirements for a population screening test}

Echocardiographic screening for RHD meets many of the requirements for disease screening. Firstly, an obvious disease burden exists that is detectable in its preclinical phase. Secondly, a suitable test is available; the echocardiographic standardization study provides the basis for critically examining the question of whether echocardiography has appropriate sensitivity and specificity as a screening tool. Thirdly, early treatment is likely to lead to better outcomes. ${ }^{7-9,129}$

Arguably the most-important gap in our knowledge is that the natural history of the condition is not fully understood. Although the natural histories of ARF and clinical RHD are known, ${ }^{3,6,7,23,130}$ whether disease progression also occurs for those with subclinical disease detected by echocardiography (without an accompanying clinical pathological murmur) is unknown for both 'definite' and 'borderline' RHD.

Other requirements of an ideal screening test include patient acceptability, defined intervals for repeating the test, adequate health-service provision for the extra clinical workload, and costs balanced against benefits. ${ }^{131}$ Regional and country-specific variations will affect how well many of these criteria are met.

We emphasize the importance of having a well-run and effective secondary prophylaxis program in place before embarking on larger-scale screening, and the capacity to upscale this program with newly detected patients. ${ }^{132}$ Countries with the highest disease burden might have the fewest resources. In some regions, screening might be considered logistically unfeasible or secondary prophylaxis insufficiently developed to recommend screening.

\section{Who to screen and how to screen}

Echocardiographic screening should only be considered in settings where a high pretest probability of RHD exists; in other words, in geographic locations with a high prevalence of RHD. The definition of 'high prevalence' is not quantified here, as many countries or regions that are planning RHD screening programs do not have reliable epidemiological data to estimate background prevalence. 
In such regions, other data might be useful indicators of a high disease burden (for example, hospitalizations for ARF, RHD, or both). Alternatively, echocardiographic screening could be considered as an epidemiological tool to help establish disease burden.

The reader is referred to an overview of optimal activesurveillance and passive-surveillance RHD programs. ${ }^{23}$ Resource-limited countries might still chose to preselect patients with pathological murmurs for echocardiography. This strategy allows a much larger population to be screened for the same monetary value. However, because auscultation is poorly sensitive at detecting echocardiographically confirmed RHD lesions, ${ }^{14,17,19,22}$ this model will invariably underestimate the burden of disease and leave many RHD cases undetected. Successful screening programs can be conducted in schools ${ }^{17,19,21}$ or be community-based. ${ }^{18,22}$

\section{Use of handheld echo machines}

An important debate around asymptomatic RHD concerns the most-appropriate model for undertaking screening in resource-poor areas. Despite the increased affordability of portable echocardiography machines over the past 5 years, they remain exorbitantly priced for most low-income countries. The ultraportable, handheld machines that have been marketed for point-of-care echocardiography in intensive care and trauma units might provide a cheaper option. ${ }^{133}$ Although these pocket-sized imaging devices are capable of producing $2 \mathrm{D}$ and color images, and are simple to use by inexperienced staff, they currently cannot perform either real-time measurements or continuouswave Doppler echocardiography. Ultraportability might not necessarily confer a major additional advantage over the existing portable machines and the smallness of the screen could actually be a potential barrier to accurate interpretation. Furthermore, these devices still require extensive testing, careful validation, and further technological refinements before widespread independent use can be recommended. ${ }^{134}$ On the basis of current information, the diagnostic criteria presented in this article should not be applied to screening using handheld machines.

\section{Management of patients identified by screening}

The uncertainty around the clinical relevance of subclinical echocardiographic changes (see the following section on future research priorities), and the absence of evidencebased management protocols, mean that treatment decisions, particularly thresholds for commencement of secondary prophylaxis, will be influenced by local needs and experience. A positive screening test should always be followed by a full clinical assessment by an appropriately qualified medical officer before initiating management, which has been highlighted as another workforce issue. ${ }^{19}$

\section{Management of definite RHD}

After a screening test is performed, we recommend that individuals with echocardiographic findings of 'definite RHD' be considered to have RHD regardless of the presence or absence of a murmur (providing other etiologies have been excluded by clinical context), and secondary prophylaxis should be offered. Notably, no data are available to estimate the likelihood that an individual with subclinical 'definite RHD' will subsequently develop an episode of ARF. However, data to support that individuals with mildly clinical 'definite RHD' will benefit the most from secondary prophylaxis exists ${ }^{7-9}$ and, therefore, withholding widely accepted treatment could be seen as unethical.

\section{Management of borderline RHD}

The 'borderline RHD' echocardiographic category was established to improve the sensitivity of the test at the expense of specificity. These echocardiographic findings are more common among children from regions where RHD is highly prevalent than those from low-prevalence regions. ${ }^{78}$ Changes consistent with 'borderline RHD' can, however, also occur in individuals considered to be at low risk for ARF. Minor changes in 'low-risk patients' should be considered as normal variants. In regions of high background prevalence of RHD, borderline echocardiographic findings (with or without associated clinical pathological murmur) are more likely to represent rheumatic changes. ${ }^{19}$ In this population, the management of 'borderline RHD' is not clear-cut. Some clinicians might choose to offer secondary prophylaxis (accepting that this strategy will inevitably lead to treatment of some healthy children), ${ }^{129}$ and some might choose close clinical follow-up and repeat echocardiography.

\section{Future research priorities}

Validation of the diagnostic criteria, including a blinded review of large series of echocardiographic studies, is a high priority. We are currently working towards a system that will allow new investigators to test their accuracy in applying the criteria using DVDs or online review of echocardiograms.

An urgent need to evaluate the clinical relevance of 'definite RHD' in the absence of a pathological murmur (that is, subclinical disease) and of 'borderline RHD' exists. A combination of studies will be needed. Highquality, normal-range data are needed for children at low risk of RHD, but living in high-prevalence regions. Follow-up studies of children with abnormal and normal echocardiograms, to compare the rate of progression of echocardiographic changes as well as subsequent incidence of ARF, should be achievable within the next 5 years. A randomized, controlled trial of secondary prophylaxis versus no prophylaxis would provide highlevel evidence, but would necessitate an international, multicenter study in regions with high-compliance to secondary prophylaxis.

Large-scale screening programs aimed at disease control, rather than just defining RHD epidemiology, are required. Economic and cost-effectiveness evaluation can then be calculated. In the meantime, mathematical models using existing data could allow prediction of effectiveness of large-scale screening programs.

Realistic estimates of disease burden should add impetus to efforts to produce an effective group A streptococcal vaccine. ${ }^{18}$ Moreover, echocardiography 
will have an important role in trials assessing the safety and the efficacy of group A streptococcal vaccines, and in RHD epidemiology for targeting vaccine delivery.

\section{Conclusions}

The purpose of these diagnostic guidelines is to define the minimum echocardiographic criteria for RHD in individuals without a clear history of ARF. The guidelines can be used in the setting of RHD screening programs or as a clinical tool when a diagnosis of RHD is being considered. In all circumstances, these guidelines should be used in conjunction with clinical findings and evidence of risk factors for RHD. Decisions to commence secondary prophylaxis, and about the duration of such treatment, should be made on the basis of local or regional guidelines wherever possible. The diagnostic echocardiographic definitions of RHD in these guidelines have been made on the basis of the best evidence available at this time and will need revision in future, as more experience is gained and research is performed. In the meantime, the investigators plan to work on a system to ensure that the criteria can be made widely available, and to support clinicians and public-health officials in all regions of the world to be able to apply them accurately.
1. Carapetis, J. R., Steer, A. C., Mulholland, E. K. \& Weber, M. The global burden of group A streptococcal diseases. Lancet Infect. Dis. 5, 685-694 (2005).

2. Special Writing Group of the Committee on Rheumatic Fever and Kawasaki Disease of the Council on Cardiovascular Disease in the Young of the American Heart Association. Guidelines for the diagnosis of rheumatic fever. Jones Criteria, 1992 update. JAMA 268, 2069-2073 (1992).

3. World Health Organisation. Rheumatic Fever and Rheumatic Heart Disease: Report of a WHO Expert Consultation, Geneva, 29 October-1 November 2001. WHO [online] www.who.int/ entity/cardiovascular_diseases/resources/ trs923/en/ (2010).

4. National Heart Foundation of Australia and the Cardiac Society of Australia and New Zealand. Diagnosis and management of acute rheumatic fever and rheumatic heart disease in Australia -an evidence-based review. Heart Foundation [online] http://www.heartfoundation.org.au/ Information-For-Professionals/ Clinical-Information/Pages/arf-rhd.aspx (2006)

5. Heart Foundation of New Zealand and Cardiac Society of Australia and New Zealand. New Zealand guidelines for rheumatic fever 1 : diagnosis, management and secondary prevention. Heart Foundation [online] http://www.heartfoundation.org.nz/uploads/ Rheumatic\%20fever\%20guideline\%201(5).pdf (2006).

6. Feinstein, A. R. et al. Rheumatic fever in children and adolescents. A long-term epidemiologic study of subsequent prophylaxis, streptococcal infections, and clinical sequelae. vi. Clinical features of streptococcal infections and rheumatic recurrences. Ann. Intern. Med. 60 (Suppl. 5), 68-86 (1964).

7. Tompkins, D. G., Boxerbaum, B. \& Liebman, J. Long-term prognosis of rheumatic fever patients receiving regular intramuscular benzathine penicillin. Circulation 45, 543-551 (1972).

8. Kassem, A. S., el-Walili, T. M., Zaher, S. R. \& Ayman, M. Reversibility of mitral regurgitation following rheumatic fever: Clinical profile and echocardiographic evaluation. Indian J. Pediatr. 62, 717-723 (1995).

9. Milliken, A. The short term morbidity of acute rheumatic fever in children and youth under the age of 20 years at first diagnosis in Auckland, 1998-1999 (The University of Auckland, Auckland, 2003).

10. Talbot, R. G. Rheumatic fever and rheumatic heart disease in the Hamilton health district: II. Long term follow-up and secondary prophylaxis. N. Z. Med. J. 97, 634-637 (1984).

11. Abbasi, A. S., Hashmi, J. A., Robinson, R. D. Jr., Suraya, S. \& Syed, S. A. Prevalence of heart disease in school children of Karachi. Am. J. Cardiol. 18, 544-547 (1966).

12. Maharaj, B. et al. Screening for rheumatic heart disease amongst black school children in Inanda, South Africa. J. Trop. Pediatr. 33, 60-61 (1987).

13. Kumar, P., Garhwal, S. \& Chaudhary, V. Rheumatic heart disease: a school survey in a rural area of Rajasthan. Indian Heart J. 44, 245-246 (1992).

14. Steer, A. C., Adams, J., Carlin, J., Nolan, T. \& Shann, F. Rheumatic heart disease in school children in Samoa. Arch. Dis. Child. 81, 372 (1999).

15. Steer, A. C. et al. High prevalence of rheumatic heart disease by clinical and echocardiographic screening among children in Fiji. J. Heart Valve Dis. 18, 327-335 (2009).

16. Marijon, E. et al. Rheumatic heart disease screening by echocardiography: The inadequacy of world health organization criteria for optimizing the diagnosis of subclinical disease. Circulation 120, 663-668 (2009).

17. Carapetis, J. R. et al. Evaluation of a screening protocol using auscultation and portable echocardiography to detect asymptomatic rheumatic heart disease in Tongan schoolchildren. Nat. Clin. Pract. Cardiovasc. Med. 5, 411-417 (2008).

18. Paar, J. A. et al. Prevalence of rheumatic heart disease in children and young adults in Nicaragua. Am. J. Cardiol. 105, 1809-1814 (2010).

19. Webb, R. H. et al. Optimising echocardiographic screening for rheumatic heart disease in New Zealand: not all valve disease is rheumatic. Cardiol. Young 21, 436-443 (2011).

20. Reeves, B. M., Kado, J. \& Brook, M. High prevalence of rheumatic heart disease in Fiji detected by echocardiography screening. J. Paediatr. Child Health 47, 473-478 (2011).

21. Bhaya, M., Panwar, S., Beniwal, R. \& Panwar, R. B. High prevalence of rheumatic heart disease detected by echocardiography in school children. Echocardiography 27, 448-453 (2010).

22. Marijon, E. et al. Prevalence of rheumatic heart disease detected by echocardiographic screening. N. Engl. J. Med. 357, 470-476 (2007).

23. Carapetis, J., Parr, J. \& Cherian, T. Standardization of epidemiologic protocols for surveillance of post-streptococcal sequelae: acute rheumatic fever, rheumatic heart disease and acute poststreptococcal glomerulonephritis. Department of Health and Human Services, National Institutes of Health [online] http://www.niaid.nih.gov/topics/ strepThroat/Documents/groupasequelae.pdf (2010).

24. Nair, R., Aggarwal, R. \& Khanna, D. Methods of formal consensus in classification/diagnostic criteria and guideline development. Semin Arthritis Rheum. 41, 95-105 (2011).

25. Scottish Intercollegiate Guidelines Network. SIGN 50: a guideline developer's handbook. Scottish Intercollegiate Guidelines Network [online] http://www.sign.ac.uk/guidelines/ fulltext/50/annexb.html (2011).

26. Jaine, R., Baker, M. \& Venugopal, K. Epidemiology of acute rheumatic fever in New Zealand 19962005. J. Paediatr. Child Health 44, 564-571 (2008).

27. Spinetto, H., Lennon, D. \& Horsburgh, M. Rheumatic fever recurrence prevention: a nurse led programme of 28 day penicillin in an area of high endemnicity. J. Paediatr. Child Health 47, 228-234 (2011).

28. Jaine, R., Baker, M. \& Venugopal, K. Acute rheumatic fever associated with household crowding in a developed country. Pediatr. Infect. Dis. J. 30, 315-319 (2011).

29. Longo-Mbenza, B. et al. Survey of rheumatic heart disease in school children of Kinshasa town. Int. J. Cardiol. 63, 287-294 (1998).

30. Sultan, F. A. et al. Rheumatic tricuspid valve disease: an evidence-based systematic overview. J. Heart Valve Dis. 19, 374-382 (2010).

31. Alkhalifa, M. S., Ibrahim, S. A. \& Osman, S. H. Pattern and severity of rheumatic valvular lesions in children in Khartoum, Sudan. East. Mediterr. Health J. 14, 1015-1021 (2007).

32. Saleh, H. K. Pattern of rheumatic heart disease in Southern Yemen. Saudi Med. J. 28, 108-113 (2007).

33. Aurakzai, H. A. et al. Echocardiographic profile of rheumatic heart disease at a tertiary cardiac centre. J. Ayub Med. Coll. Abbottabad. 21 122-126 (2009).

34. Marcus, R. H., Sareli, P., Pocock, W. A. \& Barlow, J. B. The spectrum of severe rheumatic mitral valve disease in a developing country. Correlations among clinical presentation, surgical pathological findings, and hemodynamic sequelae. Ann. Intern. Med. 120, 177-183 (1994)

35. Vasan, R. S. et al. Echocardiographic evaluation of patients with acute rheumatic fever and rheumatic carditis. Circulation 94, 73-82 (1996).

36. Yuko-Jowi, C. \& Bakari, M. Echocardiographic patterns of juvenile rheumatic heart disease at the Kenyatta National Hospital, Nairobi. East Afr. Med. J. 82, 514-519 (2005).

37. Lembo, N. J. et al. Mitral valve prolapse in patients with prior rheumatic fever. Circulation. 77, 830-836 (1988)

38. Atalay, S., Ucar, T., Ozcelik, N, , Ekici, F. \& Tutar, E. Echocardiographic evaluation of mitral valve in patients with pure rheumatic mitral regurgitation. Turk. J. Pediatr. 49, 148-153 (2007). 
39. Vijayalakshmi, I. B., Vishnuprabhu, R. O. Chitra, N., Rajasri, R. \& Anuradha, T. V. The efficacy of echocardiographic criterions for the diagnosis of carditis in acute rheumatic fever. Cardiol. Young 18, 586-592 (2008).

40. Camara, E. J., Neubauer, C., Camara, G. F. \& Lopes, A. A. Mechanisms of mitral valvar insufficiency in children and adolescents with severe rheumatic heart disease: an echocardiographic study with clinical and epidemiological correlations. Cardiol. Young 14, 527-532 (2004).

41. Kalangos, A. et al. Anterior mitral leaflet prolapse as a primary cause of pure rheumatic mitral insufficiency. Ann. Thorac. Surg. 69, 755-761 (2000).

42. Chauvaud, S. et al. Long-term (29 years) results of reconstructive surgery in rheumatic mitral valve insufficiency. Circulation 104 (12 Suppl. 1), I12-I15 (2001).

43. Skoularigis, J., Sinovich, V., Joubert, G. \& Sareli, $P$. Evaluation of the long-term results of mitral valve repair in 254 young patients with rheumatic mitral regurgitation. Circulation 90 (5 Pt 2), II167-II174 (1994).

44. Tomaru, T. et al. Postinflammatory mitral and aortic valve prolapse: a clinical and pathological study. Circulation 76, 68-76 (1987).

45. Ungar, H. \& Ben-Ishay, Z. Rheumatic and age changes of the heart in Israel: pathological and statistical study. Isr. J. Med. Sci. 1, 50-61 (1965)

46. van der Bel-Kahn, J. \& Becker, A. E. The surgical pathology of rheumatic and floppy mitral valves. Distinctive morphologic features upon gross examination. Am. J. Surg. Pathol. 10, 282-292 (1986).

47. Feigenbaum, H., Armstrong, W. F. \& Ryan, T. (Eds) Feigenbaum's Echocardiography, 6th edn Vol. 1 (Lippincott Williams \& Wilkins, Philadelphia, 2005).

48. Waller, B. F., Howard, J. \& Fess, S. Pathology of mitral valve stenosis and pure mitral regurgitation-Part I. Clin. Cardiol. 17, 330-336 (1994).

49. lung, B. et al. Valvular heart disease in the community: a European experience. Curr. Prob. Cardiol. 32, 609-661 (2007).

50. Olson, L. J., Subramanian, R., Ackermann, D. M., Orszulak, T. A. \& Edwards, W. D. Surgical pathology of the mitral valve: a study of 712 cases spanning 21 years. Mayo Clin. Proc. 62, 22-34 (1984).

51. Ratnakar, K. S., Rajagopal, P. \& Somaraju, B. Surgical pathology of mitral valves - the Indian scene. Int. J. Cardiol. 24, 124-126 (1989).

52. Wilkins, G. T., Weyman, A. E., Abascal, V. M., Block, P. C. \& Palacios, I. F. Percutaneous balloon dilatation of the mitral valve: an analysis of echocardiographic variables related to outcome and the mechanism of dilatation. Br. Heart J. 60, 299-308 (1988).

53. Moore, P. et al. Valvular heart disease: severe congenital mitral stenosis in infants. Circulation 89, 2099-2106 (1994).

54. McElhinney, D. B. et al. Current management of severe congenital mitral stenosis: outcomes of transcatheter and surgical therapy in 108 infants and children. Circulation 112, 707-714 (2005).

55. Serraf, A. et al. Congenital mitral stenosis with or without associated defects: an evolving surgical strategy. Circulation 102 (19 Suppl. 3), III166-III171 (2000).

56. Selamet Tierney, E. S. et al. Echocardiographic predictors of mitral stenosis-related death or intervention in infants. Am. Heart J. 156 , 384-390 (2008)

57. Akram, M. R., Chan, T., McAuliffe, S. \& Chenzbraun, A. Non-rheumatic annular mitral stenosis: prevalence and characteristics. Eur. J. Echocardiogr. 10, 103-105 (2009).

58. Chockalingam, A., Gnanavelu, G., Elangovan, S. $\&$ Chockalingam, V. Clinical spectrum of chronic rheumatic heart disease in India. J. Heart Valve Dis. 12, 577-581 (2003).

59. Tantchou Tchoumi, J. C. \& Butera, G. Rheumatic valvulopathies occurence, pattern and follow-up in rural area: the experience of the Shisong Hospital, Cameroon. Bull. Soc. Pathol. Exot. 102, 155-158 (2009).

60. Essien, I. O. et al. One year echocardiographic study of rheumatic heart disease at Enugu, Nigeria. Niger. Postgrad. Med. J. 15, 175-178 (2008).

61. Sani, M. U., Karaye, K. M. \& Borodo, M. M. Prevalence and pattern of rheumatic heart disease in the Nigerian savannah: an echocardiographic study. Cardiovasc. J. Afr. 18, 295-299 (2007).

62. Deshpande, J., Vaideeswar, P., Amonkar, G. \& Vasandani, S. Rheumatic heart disease in the past decade: an autopsy analysis. Ind. Heart J. 54, 676-680 (2002).

63. Ozer, O., Davutoglu, V., Sari, I., Akkoyun, D. C. \& Sucu, M. The spectrum of rheumatic heart disease in the southeastern Anatolia endemic region: results from 1900 patients. J. Heart Valve Dis. 18, 68-72 (2009).

64. Clawson, B. J. Rheumatic heart disease. An analysis of 796 cases. Am. Heart J. 20, 454-474 (1940).

65. Ba-Saddik, I. A. et al. Prevalence of rheumatic heart disease among school-children in Aden, Yemen. Ann. Trop. Paediatr. 31, 37-46 (2011).

66. Ravisha, M. S., Tullu, M. S. \& Kamat, J. R. Rheumatic fever and rheumatic heart disease: clinical profile of 550 cases in India. Arch. Med. Res. 34, 382-387 (2003).

67. Dawber, T. R. \& Stokes, J. 3rd. Rheumatic heart disease in the Framingham study. N. Engl. J. Med. 255, 1228-1233 (1956).

68. Veasy, L. G., Tani, L. Y. \& Hill, H. R. Persistence of acute rheumatic fever in the intermountain area of the United States. J. Pediatr. 124, 9-16 (1994).

69. Olson, L. J., Subramanian, R. \& Edwards, W. D. Surgical pathology of pure aortic insufficiency: a study of 225 cases. Mayo Clin. Proc. 59, 835-841 (1984).

70. Fox, E. R. et al. Epidemiology of pure valvular regurgitation in the large middle-aged African American cohort of the Atherosclerosis Risk in Communities study. Am. Heart J. 154, 1229-1234 (2007).

71. Reid, C. L., Anton-Culver, H., Yunis, C. \& Gardin, J. M. Prevalence and clinical correlates of isolated mitral, isolated aortic regurgitation, and both in adults aged 21 to 35 years (from the CARDIA study). Am. J. Cardiol. 99, 830-834 (2007).

72. Singh, J. P. et al. Prevalence and clinical determinants of mitral, tricuspid, and aortic regurgitation (the Framingham Heart Study). Am. J. Cardiol. 83, 897-902 (1999).

73. Palmieri, V. et al. Aortic root dilatation at sinuses of valsalva and aortic regurgitation in hypertensive and normotensive subjects: the Hypertension Genetic Epidemiology Network Study. Hypertension 37, 1229-1235 (2001).

74. Klein, A. L. et al. Age-related prevalence of valvular regurgitation in normal subjects: a comprehensive color flow examination of 118 volunteers. J. Am. Soc. Echocardiogr. 3, 54-63 (1990).

75. Sahasakul, Y., Edwards, W. D., Naessens, J. M. \& Tajik, A. J. Age-related changes in aortic and mitral valve thickness: implications for twodimensional echocardiography based on an autopsy study of 200 normal human hearts. Am. J. Cardiol. 62, 424-430 (1988).

76. Yaghoubi, A. R. \& Raeesi, K. Surgical pathology of excised heart valves in a referral hospital in Iran. RMJ 32, 70-72 (2007).

77. Yaghoubi, A. R. et al. A multi-center study of the pathologies of valvular heart diseases: 5 year analysis of more than 3400 patients in Iran. J. Cardiovasc. Thorac. Res. 2, 21-27 (2010).

78. Webb, R., Gentles, T., Stirling, J. \& Wilson, N. Echocardiographic findings in a low risk population for rheumatic heart disease (RHD): implications for screening [Abstract; page 283]. XVIII Lancefield International Symposium [online] http://www.lancefield2011.it/images/stories/ pdf/riassunti_definitivo lancefield.pdf (2011).

79. Brand, A., Dollberg, S. \& Keren, A. The prevalence of valvular regurgitation in children with structurally normal hearts: a color Doppler echocardiographic study. Am. Heart J. 123, 177-180 (1992).

80. Marcus, R. H. et al. Functional anatomy of severe mitral regurgitation in active rheumatic carditis. Am. J. Cardiol. 63, 577-584 (1989).

81. Wilson, N. J. \& Neutze, J. M. Echocardiographic diagnosis of subclinical carditis in acute rheumatic fever. Int. J. Cardiol. 50, 1-6 (1995).

82. Choong, C. Y. et al. Prevalence of valvular regurgitation by Doppler echocardiography in patients with structurally normal hearts by two-dimensional echocardiography. Am. Heart J. 117, 636-642 (1989).

83. Yoshida, K. et al. Color Doppler evaluation of valvular regurgitation in normal subjects. Circulation 78, 840-847 (1988).

84. Akasaka TMD. et al. Age-related valvular regurgitation: a study by pulsed Doppler echocardiography. Circulation 76, 262-265 (1987).

85. Berger, M., Hecht, S. R., Van Tosh, A. \& Lingam, U. Pulsed and continuous wave Doppler echocardiographic assessment of valvular regurgitation in normal subjects. J. Am. Coll. Cardiol. 13, 1540-1545 (1989).

86. Caldas, A. M. et al. The case for utilizing more strict quantitative Doppler echocardiographic criterions for diagnosis of subclinical rheumatic carditis. Cardiol. Young 17, 42-47 (2007).

87. Lanna, C. C. D., Tonelli, E., Barros, M. V. L. Goulart, E. M. A. \& Mota, C. C. C. Subclinical rheumatic valvitis: a long-term follow-up. Cardiol. Young. 13, 431-438 (2003).

88. Carpentier, A. Cardiac valve surgery-the "French correction". J. Thorac. Cardiovasc. Surg. 86, 323-337 (1983).

89. Anwar, A. M. et al. Validation of a new score for the assessment of mitral stenosis using realtime three-dimensional echocardiography. J. Am. Soc. Echocardiogr. 23, 13-22 (2010).

90. Umeda, T., Kuwako, K. \& Machii, K. M-mode and cross-sectional echocardiographic evaluation of rheumatic mitral valve disease. Jpn. Circ. J. 43, 297-304 (1979).

91. Wann, L. S., Feigenbaum, H., Weyman, A. E. \& Dillon, J. C. Cross-sectional echocardiographic detection of rheumatic mitral regurgitation. Am. J. Cardiol. 41, 1258-1263 (1978).

92. Naito, M., Morganroth, J., Mardelli, T. J., Chen, C. C. \& Dreifus, L. S. Rheumatic mitra stenosis:cross-sectional echocardiographic analysis. Am. Heart J. 100, 34-40 (1980).

93. Kabukcu, M., Arslantas, E., Ates, I., Demircioglu, F. \& Ersel, F. Clinical, echocardiographic, and hemodynamic characteristics of rheumatic mitral valve stenosis and atrial fibrillation. Angiology 56, 159-163 (2005). 
94. Reid, C. L., McKay, C. R., Chandraratna, P. A., Kawanishi, D. T. \& Rahimtoola, S. H. Mechanisms of increase in mitral valve area and influence of anatomic features in double-balloon, catheter balloon valvuloplasty in adults with rheumatic mitral stenosis: a Doppler and twodimensional echocardiographic study. Circulation 76, 628-636 (1987).

95. Zhou, L. Y. \& Lu, K. Inflammatory valvular prolapse produced by acute rheumatic carditis: echocardiographic analysis of 66 cases of acute rheumatic carditis. Int. J. Cardiol. 58, 175-178 (1997).

96. Murala, J. S. K. \& Kumar, A. S. Long-term results of cusp-level chordal shortening for anterior mitral leaflet prolapse. Tex. Heart Inst. J. 31, 246-250 (2004)

97. van der Bel-Kahn, J. M. D. \& Becker, A. E. M. D. The surgical pathology of rheumatic and floppy mitral valves: distinctive morphologic features upon gross examination. Am. J. Surg. Pathol. 10, 282-292 (1986).

98. Nazarian, I. H. \& Aryanpur, I. Pathology of chronic rheumatic mitral valvulitis in Iran and its surgical implications. Jpn. Heart J. 19, 1-11 (1979).

99. Leong, S. W. et al. Morphological findings in 192 surgically excised native mitral valves. Can. J. Cardiol. 22, 1055-1061 (2006).

100. Gorgulu, S. et al. Influence of different echocardiographic imaging modes on the assessment of anterior mitral leaflet thickness. J. Heart Valve Dis. 14, 204-208 (2005).

101. Hirata, K. et al. Pitfalls of echocardiographic measurement in tissue harmonic imaging: in vitro and in vivo study. J. Am. Soc. Echocardiogr. 15, 1038-1044 (2002).

102. Prior, D. L. et al. Impact of tissue harmonic imaging on the assessment of rheumatic mitral stenosis. Am. J. Cardiol. 86, 573-576 (2000).

103. Hawkins, K., Henry, J. S. \& Krasuski, R. A. Tissue harmonic imaging in echocardiography: better valve imaging, but at what cost? Echocardiography 25, 119-123 (2008).

104. Webb, R., Lean, F., Zeng, I. \& Wilson, N. Objective measurement of mitral valve thickness with and without rheumatic heart disease [Abstract]. $5^{\text {th }}$ World congress of paediatric cardiology and cardiac surgery [online], http://www.pccs2009. com/abstract/825.asp (2009).

105. Weissman, N. J. et al. In vivo mitral valve morphology and motion in mitral valve prolapse. Am. J. Cardiol. 73, 1080-1088 (1994).

106. Freed, L. A. et al. Mitral valve prolapse in the general population: the benign nature of echocardiographic features in the Framingham Heart Study. J. Am. Coll. Cardiol. 40, 1298-1304 (2002).

107. Uysal, S., Baysal, K., Balat, A. \& Yukel, M. The relationship between mitral valve prolapse and acute rheumatic fever in pediatric patients. Jpn. Heart J. 33, 585-590 (1992).

108. Wu, M. H., Lue, H. C., Wang, J. K. \& Wu, J. M. Implications of mitral valve prolapse in children with rheumatic mitral regurgitation. J. Am. Coll. Cardiol. 23, 1199-1203 (1994).

109. Gometza, B., al-Halees, Z., Shahid, M., Hatle, L. K. \& Duran, C. M. Surgery for rheumatic mitral regurgitation in patients below twenty years of age. An analysis of failures. J. Heart Valve Dis. 5, 294-301 (1996).
110. Perier, P. Surgical repair of the prolapsing anterior leaflet with chordal shortening. Sem. Thorac. Cardiovasc. Surg. 16, 174-181 (2004).

111. Kumar, A. S., Talwar, S., Saxena, A., Singh, R. \& Velayoudam, D. Results of mitral valve repair in rheumatic mitral regurgitation. Interact. Cardiovasc. Thorac. Surg. 5, 356 (2006).

112. Bernal, J. M., Rabasa, J. M., Vilchez, F. G., Cagigas, J. C. \& Revuelta, J. M. Mitral valve repair in rheumatic disease. The flexible solution. Circulation 88, 1746-1753 (1993).

113. Stark, J., De Leval, M., Tsang, V. T. (Eds) Surgery for Congenital Heart Defects $3^{\text {rd }}$ edn (John Wiley \& Sons Ltd, London, 2006).

114. Barlow, J. B. Aspects of active rheumatic carditis. Aust. N. Z. J. Med. 22 (5 Suppl.), 592-600 (1992).

115. American College of Cardiology/American Heart Association Task Force on Practice Guidelines et al. ACC/AHA 2006 guidelines for the management of patients with valvular heart disease: a report of the American College of Cardiology/American Heart Association Task Force on Practice Guidelines (writing committee to revise the 1998 guidelines for the management of patients with valvular heart disease): developed in collaboration with the Society of Cardiovascular Anesthesiologists: endorsed by the Society for Cardiovascular Angiography and Interventions and the Society of Thoracic Surgeons. Circulation 114, e84-e231 (2006).

116. Baird, C. W., Constantinos, C., Lansford, E. \& Pigula, F. A. Mitral valve chordal rupture masquerades as endocarditis. Pediatr. Cardiol. 28, 297-299 (2007).

117. Jeresaty, R. M., Edwards, J. E. \& Chawla, S. K. Mitral valve prolapse and ruptured chordae tendineae. Am. J. Cardiol. 55, 138-142 (1985).

118. Weidenbach, M., Brenner, R., Rantamaki, T. \& Redel, D. A. Acute mitral regurgitation due to chordal rupture in a patient with neonatal Marfan syndrome caused by a deletion in exon 29 of the FBN1 gene. Pediatr. Cardiol. 20, 382-385 (1999).

119. Gabbay, U. \& Yosefy, C. The underlying causes of chordae tendinae rupture: a systematic review. Int. J. Cardiol. 143, 113-118 (2010).

120. Cohen, G. I. et al. Color Doppler and twodimensional echocardiographic determination of the mechanism of aortic regurgitation with surgical correlation. J. Am. Soc. Echocardiogr. 9, 508-515 (1996).

121. Myers, P. O. et al. Aortic valve repair by cusp extension for rheumatic aortic insufficiency in children: long-term results and impact of extension material. J. Thorac. Cardiovasc. Surg. 140, 836-844 (2010).

122. Bernal, J. M. et al. Repair of nonsevere rheumatic aortic valve disease during other valvular procedures: is it safe? J. Thorac. Cardiovasc. Surg. 115, 1130-1135 (1998).

123. Talwar, S., Saikrishna, C., Saxena, A. \& Kumar, A. S. Aortic valve repair for rheumatic aortic valve disease. Ann. Thorac. Surg. 79 1921-1925 (2005).

124. Bozbuga, N. et al. Midterm results of aortic valve repair with the pericardial cusp extension technique in rheumatic valve disease. Ann. Thorac. Surg. 77, 1272-1276 (2004).
125. Grinda, J. M. et al. Aortic cusp extension valvuloplasty for rheumatic aortic valve disease: midterm results. Ann. Thorac. Surg. 74, 438-443 (2002).

126. Tekumit, H. et al. Cusp shaving for concomitant mild to moderate rheumatic aortic insufficiency. J. Cardiac Surg. 25, 16-22 (2010).

127. Sashida, Y. et al. Ethnic differences in aortic valve thickness and related clinical factors. Am. Heart J. 159, 698-704 (2010).

128. Shapiro, L. M., Thwaites, B., Westgate, C. $\&$ Donaldson, R. Prevalence and clinical significance of aortic valve prolapse. Br. Heart J. 54, 179-183 (1985).

129. Bhaya, M., Beniwal, R., Panwar, S. \& Panwar, R. B. Two years of follow-up validates the echocardiographic criteria for the diagnosis and screening of rheumatic heart disease in asymptomatic populations. Echocardiography 28, 929-933 (2011).

130. Carapetis, J. R., Brown, A., Wilson, N. J. \& Edwards, K. N. An Australian guideline for rheumatic fever and rheumatic heart disease: an abridged outline. Med. J. Aust. 186, 581-586 (2007).

131. Council of Europe Committee of Ministers. Recommendation no. R(94)11 of the Committee of Ministers to the Member Sates on screening as a tool of preventative medicine. Council of Europe [online] https://wcd.coe.int/wcd/ com.instranet. InstraServlet?command=com. instranet.CmdBlobGet\&Instranetlmage $=534532$ \&SecMode $=1 \&$ Docld $=514336 \&$ Usage $=2$ (1994).

132. McDonald, M., Brown, A., Noonan, S. \& Carapetis, J. R. Preventing recurrent rheumatic fever: the role of register based programmes. Heart 91, 1131-1133 (2005).

133. Galderisi, M. et al. Improved cardiovascular diagnostic accuracy by pocket size imaging device in non-cardiologic outpatients: the NaUSiCa (Naples Ultrasound Stethoscope in Cardiology) study. Cardiovasc. Ultrasound 8, 51 (2010).

134. Sicari, R. et al. The use of pocket-size imaging devices: a position statement of the European Association of Echocardiography. Eur. J. Echocardiogr. 12, 85-87 (2011).

\section{Acknowledgments}

We acknowledge the support of RHDAustralia and Heart Association of Thailand in coordinating the investigators' meeting. B. Reményi's research position was funded by research scholarships from the National Heart Foundation of New Zealand and the Lowitja Institute of Australia. N. Wilson was funded part time by the Green Lane Research and Education Fund in 2010. L. Zühlke is supported by the NIH through the international clinical scholars and fellow program (R24 TW007988). Project grants were received from the Medtronic Foundation for the investigators' meeting and from the Green Lane Research and Education Fund for the website development.

\section{Author contributions}

B. Reményi wrote the article. All authors researched data for the article, substantially contributed to discussion of the content, and reviewed/edited the manuscript before submission.

Supplementary information is linked to the online version of the paper at www.nature.com/nrcardio. 